Pérez, Jorge; Ayala, Citlali. Diagnóstico de cooperación internacional para el desarrollo mexicana y su andamiaje institucional actual.

\title{
DIAGNÓSTICO DE LA COOPERACIÓN INTERNACIONAL PARA EL DESARROLLO MEXICANA Y SU ANDAMIAJE INSTITUCIONAL ACTUAL ${ }^{1}$
}

\section{SURVEY ON INTERNATIONAL COOPERATION FOR DEVELOPMENT IN MEXICO AND ITS CURRENT INSTITUTIONAL FRAMEWORK}

\author{
JORGE PÉREZ \\ Instituto Mora / Universidad Anáhuac México \\ japerpe@yahoo.com \\ CITLALI AYALA \\ Instituto de Investigaciones Dr. José María Luis Mora \\ cayala@mora.edu.mx
}

Fecha de recepción: febrero 2016

Fecha de aceptación: marzo 2016

\section{RESUMEN}

Ante el proceso de tránsito de los Objetivos de Desarrollo del Milenio hacia los Objetivos de Desarrollo Sostenible a partir de 2016, y ante una mayor formalización de la cooperación internacional en México a partir de la creación de la Agencia Mexicana de Cooperación Internacional para el Desarrollo en 2011, es pertinente conocer la percepción actual de la cooperación internacional en el país. Así, el presente artículo presenta los principales hallazgos del diagnóstico realizado en 2014 entorno a la opinión de líderes y expertos sobre las tendencias observadas sobre los principales retos e implicaciones para México como país receptor, donante o dual y para su política exterior, pero sobre todo para una mejor ejecución y participación en la Agenda 2030.

PALABRAS CLAVE: Cooperación Internacional, Desarrollo

\begin{abstract}
Facing the transition of the Millennium Development Goals towards the Sustainable Development Goals from 2016 onwards, and facing a more formal cooperation in Mexico with the creation of its Agency in 2011, it becomes relevant to know the current situation on the international cooperation in the country. Hence, the current paper, summarize the main outcomes of an opinion survey based on the point of view of leaders and experts on the subject, that was applied along 2014 over observed trends on challenges and implications for Mexico, either as a recipient, donor or dual country and for its foreign policy, but mainly for the participation and execution of the 2030 Agenda.
\end{abstract}

\footnotetext{
${ }^{1}$ El presente trabajo muestra los aspectos más relevantes de un estudio más amplio realizado entre 2014 y 2015 publicado en 2016.
} 
Pérez, Jorge; Ayala, Citlali. Diagnóstico de cooperación internacional para el desarrollo mexicana y su andamiaje institucional actual.

KEY WORDS: International Cooperation, Development

JEL: F5, O19

\section{INTRODUCCIÓN}

Ante el fin de los Objetivos de Desarrollo del Milenio (ODM) y el inicio de los próximos objetivos que marcaran la agenda internacional de la Cooperación Internacional para el Desarrollo (CID) a partir del 2016, los Objetivos de Desarrollo Sustentable (ODS), cabe reflexionar sobre las tendencias y la percepción que se tiene en México sobre la cooperación internacional.

Adicionalmente, a raíz de la creación de la Agencia Mexicana de Cooperación Internacional para el Desarrollo (AMEXCID) en 2011 y de una mayor formalización y articulación de la cooperación internacional en el país con la Ley Cooperación Internacional para el Desarrollo (LCID), se vuelve relevante conocer la opinión de líderes y expertos sobre las tendencias e intereses sobre la cooperación mexicana, considerando que la creación de la agencia tendrá implicaciones sobre el papel de México como país receptor, donante o dual.

Por ello, como parte del trabajo académico realizado en el Instituto Mora, entorno al programa de investigación en cooperación internacional, desarrollo y políticas públicas, se detectó la necesidad de contar con un diagnóstico que nos permitiera conocer más de cerca las tendencias y escenarios posibles de la Cooperación Internacional Mexicana en el contexto actual, a fin de poder enfrentar de mejor forma los retos que la agenda internacional plantea a la política exterior mexicana y en particular a la cooperación internacional y sus instituciones relevantes.

Así, con el apoyo del Centro de Estudios de Opinión Publica (CEOP) de la Facultad de Ciencias Políticas y Sociales (FCPyS) de la Universidad Nacional Autónoma de México (UNAM), y con el apoyo del Instituto de Investigaciones Dr. José María Luis Mora, a través de la "Convocatoria interna para financiar proyectos de investigación 2014", realizamos dicho estudio".

Para ello la primera sección destaca el enfoque del liberalismo institucional en que se encuadra este trabajo, para en la segunda sección, contextualizar sobre los estudios entorno a la cooperación como el que aquí se presenta, y finalmente, en la sección tres, hacer una síntesis de los principales hallazgos del diagnóstico realizado entre los meses de junio y julio del 2014 así como de la metodología del estudio. Por último, se presentan algunas reflexiones sobre la materia.

\footnotetext{
${ }^{2}$ Se agradece al Dr. Fernando Castañeda Sabido director de la Facultad de Ciencias Políticas y Sociales de la UNAM, al Mtro. Felipe de la O López Coordinador del CEOP y co-coordinador del estudio, así como al Dr. Luis Jáuregui Director General del Instituto Mora y la Dra. Cristina Sacristán, Directora de Investigación, así como al equipo de investigadores y becarios que colaboraron en este estudio.
} 
Pérez, Jorge; Ayala, Citlali. Diagnóstico de cooperación internacional para el desarrollo mexicana y su andamiaje institucional actual.

\section{EL ANDAMIAJE ORGANIZACIONAL VISTO BAJO EL ENFOQUE DEL LIBERALISMO INSTITUCIONAL}

De manera general, las preguntas del estudio se dieron bajo el contexto mundial de la agenda 2030 y el papel de la AMEXCID en ese proceso. Al respecto es necesario señalar lo siguiente: en el marco global dos procesos han marcado la ruta de la llamada nueva arquitectura de la ayuda en los últimos diez años: el proceso del Foro de Alto Nivel sobre la Eficacia de la Ayuda, desde 2005 con la Declaración de París, y la transición de la implementación de los Objetivos de Desarrollo del Milenio de 2000 a 2015 hacia la Agenda de Desarrollo 2030 y la correspondiente aprobación de los ODS.

Frente a estos procesos, la política exterior de México, a través de la Secretaria de Relaciones Exteriores (SRE) y la AMEXCID, jugó un papel sustantivo al albergar el foro de la Alianza Global para la Cooperación Eficaz del Desarrollo (AGCED) en 2014 en la Ciudad de México, misma que materializa el octavo ODM que dicta la conformación de una asociación global para el desarrollo. Al mismo tiempo, el andamiaje institucional mexicano en materia de cooperación para el desarrollo comenzaba su proceso de fortalecimiento al aprobarse el Programa de Cooperación Internacional para el Desarrollo (PROCID) y reestructurarse la AMEXCID el mismo año.

Ambos eventos permitieron a las instituciones mexicanas responsables del tema movilizar sus cuadros diplomáticos para contar con un foro exitoso y generar resultados que dotarían de continuidad a la efectividad de la ayuda, esta vez enfocados en el desarrollo. Por el otro, agilizaron un proceso de institucionalización nacional que contara con un área de planeación y formulación de política pública de cooperación internacional para el desarrollo, así como desarrollar metodologías de evaluación y monitoreo no sólo de la cooperación recibida y ofertada, sino también que paulatinamente coadyuven a la implementación y el seguimiento de los ODS.

En términos generales, las teorías de relaciones internacionales bajo las cuales ha sido posible a lo largo del tiempo analizar esta área del conocimiento e interpretar sus procesos son: el realismo político, el liberalismo, el marxismo y el constructivismo, con sus respectivas derivaciones en el neorrealismo y realismo estructural, neoliberalismo e interdependencia compleja, institucionalismo neoliberal, y constructivismo moderado (Salomón, 2001 y Pauselli, 2013).

De ellos, el enfoque del liberalismo institucional nos permite interpretar los hallazgos del diagnóstico en función de sus procesos y su convergencia con la agenda de desarrollo 2030 y los ODS, así como en la consolidación de la AGCED, que pueden ser considerados como regímenes internacionales emergidos de condiciones consensuadas por la comunidad internacional. En ese sentido, en concordancia con el régimen internacional de la cooperación para el desarrollo, las acciones estatales dependen de los acuerdos internacionales prevalecientes que implican cumplimiento de compromisos creíbles y la capacidad de los Estados para comunicarse y cooperar desde las instituciones hechas para tales efectos (Keohane, 1993). Krasner citado por Schiavon (2014) soporta esta idea al considerar un régimen internacional como el conjunto de 
Pérez, Jorge; Ayala, Citlali. Diagnóstico de cooperación internacional para el desarrollo mexicana y su andamiaje institucional actual.

principios implícitos y explícitos, normas, reglas y procesos de toma de decisiones donde las expectativas de actores convergen en un área determinada de las relaciones internacionales. Bajo la perspectiva de este autor, por otro lado, estos procesos pertenecerían a un liberalismo interdependiente, en el que el mayor acercamiento y contacto entre dos o más países en múltiples aspectos aumentará la interdependencia entre sí, y se generarían mecanismos de cooperación en múltiples entidades de los países participantes. Esto es comprobable a través del multilateralismo tradicional, así como de la AGCED y los mecanismos de implementación y seguimiento de los ODS que crean actualmente. Asimismo, el fin de esas reglas y normas pueden ser formales 0 informales y se traduce en promover procesos institucionalizados en los que las acciones y resultados sean durables y predeterminados (Schiavon, 2014); en ese sentido, la AMEXCID tiene la guía nacional con el PROCID y la internacional con la agenda 2030, por lo cual lograr la convergencia con la AGCED implica que la consolidación institucional de la agencia sea fundamental.

En el caso de la AMEXCID, visto bajo las tres dimensiones de la institucionalización de Keohane (1993), se consideraría que la especificidad se logra en la medida en que la ley de CID y el PROCID especifican alineación hacia la agenda de desarrollo; se posee una autonomía limitada, siendo que la agencia no puede alterar sus propias reglas y depende de la Secretaría de Relaciones Exteriores; y, finalmente, que su sentido de comunidad es paulatino y progresivo, al contar con un Consejo Consultivo y una serie de Comités Mixtos que incluyen a instituciones académicas, sector privado y sociedad civil para ser partícipes de determinados procesos de toma de decisión. Al observarse que los primeros debates de la Agenda 2030 fueron atendidos por la Secretaría de Relaciones Exteriores y la Presidencia de la República, puede afirmarse que, si bien la AMEXCID cuenta con cinco años de existencia y un relativamente rápido fortalecimiento, como afirma Keohane, no debería darse por sentado que la creciente institucionalización lleva a una mayor eficacia. Por tal razón, el proceso es paulatino y no cabe duda que el cambio de personal en la Dirección Ejecutiva y la incorporación de personal experto en el tema, dota a la agencia mexicana del liderazgo que propicie dicha eficacia.

Por último, Prado argumenta que uno de los principales supuestos de liberalismo (en particular el de perfil institucional) indica que la estructura y diseño de instituciones colectivas y organizaciones nacionales e internacionales juegan un papel clave, lo cual el autor enlaza con la promoción de procesos de gobernabilidad, en tanto el fin de sus instituciones, normas y procesos dirigen y regulan el comportamiento de sus actores y respectivas instituciones (Prado, 2014).

\section{VALORACIÓN DE LOS ESTUDIOS SOBRE COOPERACIÓN INTERNACIONAL EN EL CONTEXTO ACTUAL}

El año 2000 marcaría un punto de inflexión en el rumbo de la agenda internacional del desarrollo con el lanzamiento de los objetivos de desarrollo del milenio al que concurrirían la mayor parte de los países miembros de Naciones Unidas. Los ocho objetivos y dieciséis metas buscarían disminuir la pobreza en el mundo, así como aspectos 
Pérez, Jorge; Ayala, Citlali. Diagnóstico de cooperación internacional para el desarrollo mexicana y su andamiaje institucional actual.

relacionados a esta como la mejora en la educación, en la salud, en la disminución de la mortalidad, en la disminución de enfermedades como la malaria o el VIH, o el cuidado del medio ambiente y la consolidación de una alianza mundial para el desarrollo 3 .

En esa línea, autores como Carbonnier y Sumner (2012) o Klingebiel (2014, pp. 89-90) entre otros, dan cuenta de estos cambios, caracterizados por tres grandes revoluciones identificadas por Severino y Ray (2009, pp. 2-8) como:

- Un nuevo grupo de retos para la política pública global: los ODM y los Bienes Públicos Globales (y a partir de 2016 en los ODS).

- Un nuevo grupo de actores con mayor influencia y aportaciones financieras a las políticas públicas globales entre los que destaca el sector privado 4 .

- Una nueva "caja de herramientas", centrada en "formas innovadoras de financiamiento para el desarrollo", entre las que destacan: fondos financieros, impuestos sobre billetes aéreos, capitales de riesgo, seguros, entre otros.

Este proceso detonaría una serie de cumbres, e iniciativas que facilitarían el cumplimento de los ODM. En tal proceso, la comunidad internacional y la académica, han estado muy activos dando seguimiento y analizando todos estos procesos. Lo cual también, ha creado la necesidad de evaluar distintos sectores y distintos grupos de interés entorno a: opinión, tendencias, impacto y apropiación de la Cooperación Internacional y su agenda. Se abriría también el debate sobre conceptos clave y refrendados en la Declaración de Paris (2005), como: la rendición de cuentas (por ejemplo para los contribuyentes), la transparencia (de las actividades de los gobiernos y sus socios) o la gestión orientada a resultados (de los impactos de las acciones y recursos utilizados) ${ }^{5}$.

México no ha sido ajeno a estos procesos, lo que desde 2007 le llevo a un proceso por formalizar la institucionalidad de la cooperación mexicana ${ }^{6}$, que finalmente, en 2011 se materializaría en la creación de la ley mexicana de cooperación internacional y su consecuente andamiaje institucional o "Sistema Mexicano de Cooperación Internacional", que se estructura en 5 grandes ejes como se muestra en la tabla $1^{7}$.

\footnotetext{
${ }^{3}$ Para más detalle, véase el sitio oficial de los ODM, http://www.un.org/es/millenniumgoals/bkgd.shtml.

${ }^{4}$ Se suelen reconocer iniciativas como: la Alianza Global para Vacunas e Inmunización (GAVI por sus siglas en ingles), el Fondo Global contra el SIDA, la Iniciativa de Transparencia en la Industria Extractiva (EITI en inglés), o el Fondo Mundial para el Medio Ambiente (GEF por sus siglas en ingles), adicionalmente se identifican, la filantropía corporativa global, la creación de fondos globales, negocios orientados a los pobres o inversión social.

${ }^{5}$ En este contexto se identifican distintos esfuerzos que buscan sistematizar y proveer herramientas de medición en distintos niveles y temáticas. Por ejemplo, desde Naciones Unidas, el Foro de Cooperación para el Desarrollo (DCF), prepararía una serie de documentos sobre "Rendición de cuentas mutua y transparencia" sobre resultados de cooperación internacional a partir del 2009 (ECOSOC, 2012). Dando continuidad a estos trabajos Ocampo y Gómez (2014) y Ocampo (2015) se centrarían en "Rendición de cuentas y efectividad de la cooperación al desarrollo" así como en la generación de un marco de monitoreo y rendición de cuentas en el contexto Post 2015. Por último, se encuentran distintos trabajos con visiones micro o macro sobre evaluación de la gestión o impacto de la cooperación como los de Alonso (2012), Duflo y Kremer (2003), o González (2005).

${ }^{6}$ Cabe resaltar que al igual que México, muchos otros países, particularmente emergentes, como Brasil, Turquía, Sudáfrica, Indonesia, entre otros, han transitado por procesos similares al mexicano en los últimos años, al respecto se recomienda ver Sidiropoulos, Pérez-Pineda, Chaturvedi y Fues (2015).

${ }^{7}$ El presente estudio se centra en la revisión de la cooperación mexicana en el contexto de consolidación del Sistema Mexicano de Cooperación a partir del 2011. Sin embargo, existe una amplia literatura que explica y abunda sobre el
} 
Pérez, Jorge; Ayala, Citlali. Diagnóstico de cooperación internacional para el desarrollo mexicana y su andamiaje institucional actual.

Tabla 1- Sistema mexicano de cooperación internacional

\begin{tabular}{|c|c|}
\hline Pilar & Brazo institucional \\
\hline Pilar Jurídico & Ley de cooperación internacional para el desarrollo (LCID) \\
\hline Pilar Administrativo & Agencia Mexicana de Cooperación Internacional para el Desarrollo \\
(AMEXCID)
\end{tabular}

En ese contexto, internacional y nacional, se hace pertinente diagnosticar el estado actual de la cooperación. Derivado de ello, se detectaron una serie de iniciativas que en diversos países con distintos objetivos que coincidirían en valorar la opinión de expertos y del público en general sobre lo que se viene haciendo en la materia de cooperación y ayuda oficial al desarrollo. Así, como antecedente al estudio realizado, se presentan algunas de estas iniciativas ${ }^{8}$.

En el caso español por ejemplo, se detectaron distintas iniciativas provenientes de actores diversos como la academia, la sociedad civil, grupos especializados y entidades públicas. Entre ellos, la Universidad de Cantabria ha realizado en un par de ocasiones desde el 2010, el estudio sobre "Percepción de la comunidad universitaria de la UC sobre la cooperación internacional para el desarrollo, comercio justo y voluntariado". La Asociación Española de Pediatría elaboró el diagnostico "Los pediatras y la Cooperación Internacional" en 2012, para ampliar el interés del gremio en la CID.

Por su parte el Centro de Investigaciones Sociológicas de España (CIS) realiza de manera continua distintas encuestas, entre ellas, ha realizado durante varios años, sondeos sobre el grado de interés de los españoles por las realidades de otros países, en particular, sobre percepciones y actitudes entorno a la cooperación internacional y ayudas al desarrollo, como lo muestra su barómetro de diciembre de 2007 No 2746. En esa línea la Fundación Carolina junto con el CIS, publicó entre el 2005 y el 2010 el barómetro "América Latina y la cooperación al desarrollo en la opinión pública española". 9

contexto previo de este proceso, al respecto se pueden consultar las siguientes fuentes: Soria (2008), Alcázar (2009), Ayala y Pérez (2009), Cruz (2008), Lozoya (1999) y Prado (2014), entre otros.

${ }^{8}$ Se retoman algunos ejemplos de la sección elaborada por Zarco, Castro y Martínez (2015, pp. 31-34) para este estudio y se complementan con otras experiencias.

${ }^{9} \mathrm{Al}$ respecto se recomienda ver, http://www.aeped.es/grupo-cooperacion-internacional/noticias/resultados-encuestasobre-cooperacion-internacional-2012,

http://www.cis.es/cis/opencms/ES/8_cis/boletines_PI/Boletin5/PDF/COOPERACION.pdf 
Pérez, Jorge; Ayala, Citlali. Diagnóstico de cooperación internacional para el desarrollo mexicana y su andamiaje institucional actual.

En cuanto a algunas experiencias en otros países y desde otros actores, podemos destacar: la Red Argentina Para la Cooperación Internacional, que ha realizado encuestas de percepción sobre el trabajo de redes de cooperación con sus miembros a fin de conocer el valor agregado de sus actividades o bien reorientarlas.

En Irlanda, desde la sociedad civil, la experiencia de Dóchas (The Irish Association of Non-Governmental Development Organisations) con el estudio, "Attitudes Towards Development Cooperation in Ireland" en 2013, proporcionaría información relevante para valorar el estado de situación en el país sobre la cooperación internacional.

De manera similar, Desde los think tanks, se encontraron experiencias como la del Overseas Development Institute (ODI), que junto con el Institute for Public Policy Research, llevarían a cabo en 2012 el estudio de opinión "Understanding public attitudes to aid and development" en concordancia con otras iniciativas desde el ámbito gubernamental como la realizada en 2010 por el Department for International Development del Reino Unido (DFID), sobre "Public Attitudes Towards Development", evaluando el apoyo de la sociedad británica y actores clave sobre temas como el apoyo público a la ayuda al exterior, percepciones sobre la efectividad de esta ayuda y particularmente sobre el rol de su país.

A nivel europeo, la Comisión Europea, a través de su Eurobarómetro, evaluaría también la percepción de la ayuda al desarrollo entre 2004-2005, a través del estudio "Attitudes towards development aid", en la línea de los estudios anteriores.

En el espacio latinoamericano, La Organización de Estados Americanos (OEA) y la Red Interamericana de Protección Social junto con otras instituciones del gobierno de Brasil, organizaciones de la sociedad civil y representaciones de gobiernos provenientes de Chile, Colombia, Uruguay o México, han coordinado desde el 2010 el sondeo sobre "Política Social y Cooperación Internacional: Desafío para los Ministerios de Desarrollo Social y la Red Interamericana de Protección Social”, a fin de contribuir a mejorar el ejercicio de la $\mathrm{Cl}$ en el ámbito de la protección social.

En concordancia con este tipo de estudios, y ante el fin de los ODM, la comunidad internacional está expectante sobre los ODS que entraran en vigor en el 2016, los cuales se caracterizan grosso modo por buscar su aplicación universal, es decir, que sean atendidos por todos los países del mundo sin importar su nivel de renta o grado de desarrollo; que se centren en las personas y no en grupos calificados como vulnerables; y, que logren una convergencia de esfuerzos de países desarrollados y en desarrollo, así como de las esferas multilaterales y asociaciones inclusivas como la Alianza Global para la Cooperación Eficaz del Desarrollo.

Tal proceso, alienta la elaboración de diagnósticos como el que se ha realizado y plantea la necesidad de ampliar la frecuencia, los actores involucrados y la posibilidad de hacer estudios comparativos con otros países. 
Pérez, Jorge; Ayala, Citlali. Diagnóstico de cooperación internacional para el desarrollo mexicana y su andamiaje institucional actual.

\section{TENDENCIAS OBSERVADAS DE LA COOPERACIÓN MEXICANA}

Desde el punto de vista metodológico, el estudio se apoyó de manera inicial en un focus group con expertos de academia, sociedad civil y gobierno federal, el cual tuvo la finalidad de validar el cuestionario aplicado; también se realizaron una serie de entrevistas a personalidades representativas de los distintos actores de la cooperación en México, tales como: la Asociación latinoamericana de Organizaciones de Promoción al Desarrollo A.C. por Sociedad civil (ALOP), Fundación Ford como representante de sector privado y filantropía, la Agencia Mexicana de Cooperación Internacional Para el Desarrollo (AMEXCID) por gobierno federal, la Comisión Económica Para América Latina y el Caribe (CEPAL) por organismos internacionales, el Instituto Nacional para el Federalismo y el Desarrollo Municipal (INAFED), la oficina de Asuntos Internacionales del Gobierno del Estado de México por funcionarios de gobierno estatal, y la Dirección General de Cooperación e Internacionalización (DGECI) de la UNAM por academia.

Una de los primeros resultados de tal ejercicio, fue la creación de una base de datos de aproximadamente 700 profesionales/expertos identificados en materia de cooperación internacional, pertenecientes a una gran diversidad de instituciones que realizan cooperación internacional en México y agrupados para fines de este estudio, en ocho vertientes que serían la población objeto de estudio: (1) funcionarios del gobierno federal, (2) funcionarios del gobierno estatal y gobierno del distrito federal, (3) funcionarios de organizaciones de la sociedad civil, (4) académicos, (5) funcionarios de la iniciativa privada, (6) funcionarios de organismos internacionales, (7) funcionarios de agencias de cooperación internacional y (8) think tanks (en este último grupo se consideraron también consultores).

Es interesante este primer aspecto, pues no existe una base de datos o directorio de expertos en el campo de estudio y no fue fácil consolidar tal información de forma actualizada ante la dispersión de la misma, ya que no es un tema muy visible o claro todavía en muchas entidades públicas, privadas o de la sociedad civil.

Los conceptos, temas o áreas de interés de la cooperación internacional y mexicana referidos en el estudio, tales como: cooperación internacional, modalidades de cooperación y áreas de actividad de la agencia entre otros, se tomaron conforme a las definiciones y particularidades establecidas en la LCID, especialmente lo referido en el titulo primero y segundo de la ley, a fin de capturar la realidad de la cooperación mexicana. Así, por ejemplo, se partió del concepto de CID establecido por la ley:

"La cooperación internacional para el desarrollo comprende la transferencia, recepción e intercambio de recursos, bienes, conocimientos y experiencias educativas, culturales, técnicas, científicas, económicas y financieras con otros países, así como con organismos internacionales". (DOF, 2014)

El objetivo general del estudio fue "realizar un diagnóstico de opinión con profesionales y expertos ${ }^{10}$ de forma sistematizada sobre cuestiones clave para la Cooperación

\footnotetext{
${ }^{10}$ El perfil de profesionales y expertos de este estudio comprende a toda persona perteneciente al ámbito de la academia, sociedad civil, think tanks, organismos internacionales, sector privado o gobierno federal y estatal que esté
} 
Pérez, Jorge; Ayala, Citlali. Diagnóstico de cooperación internacional para el desarrollo mexicana y su andamiaje institucional actual.

Internacional para el Desarrollo en México". Complementariamente, como objetivos específicos se plantearon: 1- conocer la percepción de los profesionales y expertos sobre la relevancia de la cooperación internacional para el desarrollo en México, y 2- identificar tendencias, opiniones e intereses de los profesionales y expertos sobre la cooperación internacional para el desarrollo en México ${ }^{11}$.

Una vez definida la encuesta, se aplicó el levantamiento de la misma en formato digital del 2 de junio al 24 de julio de 2014. Descartando cuestionarios no respondidos e incompletos, se tuvo una tasa de respuesta aproximada de $24 \%$.

El instrumento contempló la siguiente estructura:

- Percepción general de Cooperación Internacional para el desarrollo

- Percepción de la Cooperación Internacional para el desarrollo en México

- Agencia Mexicana de Cooperación Internacional para el Desarrollo

- Información sobre el perfil de los encuestados

Así, el análisis general de los resultados arrojaría los siguientes aspectos. En cuanto a los perfiles de los encuestados, la mayor parte (52\%) fue del género femenino y el $49 \%$ del género masculino, cuya antigüedad en los cargo, osciló principalmente en más de 10 años (por un $37 \%$ ) y entre 1 a 3 años (32\%).

En la mayoría de los casos los entrevistados contaron con estudios en relaciones internacionales (66\%). Uno de los problemas observados entorno a estos temas, es que la rotación en puestos de áreas de cooperación internacional es muy alta, sobre todo en el gobierno, afectando los procesos de gestión, planeación, vinculación y seguimiento de proyectos, programas o iniciativas. El origen de los participantes se dividió en: gobierno federal (agrupado junto con el estatal y local) con $46 \%$, academia (33\%) y en menor medida el resto de sectores, destacando Agencias de cooperación (destacando en número los de la AMEXCID), funcionarios de organismos internacionales, think tanks y sociedad civil organizada, en ese orden.

Respecto a la primera sección de la encuesta, el objetivo fue conocer la percepción de los expertos sobre la CID, su concepto, funciones, actores y temas. Entre los principales resultados de esta sección podemos destacar lo siguiente: se tuvo una percepción muy variada sobre lo que podemos entender por cooperación internacional. El consenso es que no hay un concepto único, que podría variar según el actor encuestado y se percibe siempre en constante evolución.

Respecto a qué actores son los prioritarios para atender los temas de la CID, la gráfica 1 muestra que sobresalió el gobierno con $77.1 \%$, seguidos de los organismos multilaterales con $51.2 \%$, quedando en tercer lugar la sociedad civil organizada con $21.8 \%$. Respecto a los temas que se considera atiende y debe atender la CID, se priorizaron tres según la

vinculado al ámbito de la cooperación internacional desde su actividad laboral, práctica o intelectual, de lo que abundamos más adelante.

${ }^{11}$ El diagnostico no se planteó una hipótesis particular, toda vez que el estudio fue exploratorio a fin de obtener información en los ámbitos señalados que permitieran observar tendencias y opiniones en la materia. 
Pérez, Jorge; Ayala, Citlali. Diagnóstico de cooperación internacional para el desarrollo mexicana y su andamiaje institucional actual.

gráfica 2: el combate a la pobreza con $24.3 \%$, la promoción del desarrollo sustentable con $14.7 \%$ y el aumento del nivel educativo con $14.1 \%$.

\section{Gráfica 1}

¿Quién o quiénes considera usted que son los principales actores que llevan a la práctica la cooperación internacional para el desarrollo?

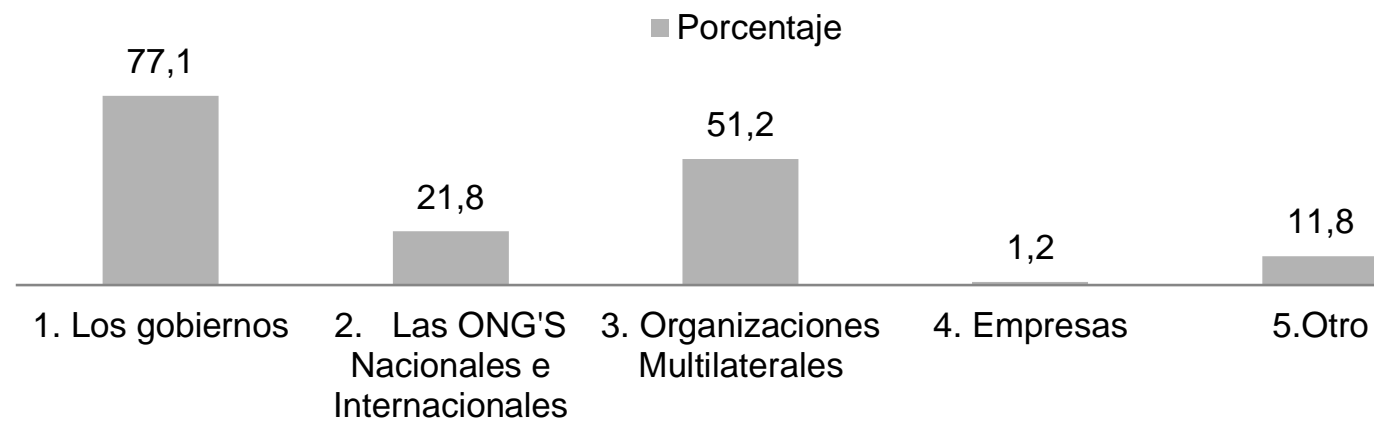

Fuente: elaboración propia

Gráfica 2

¿Que temas cree usted que atiende (y debería atender) la CID?

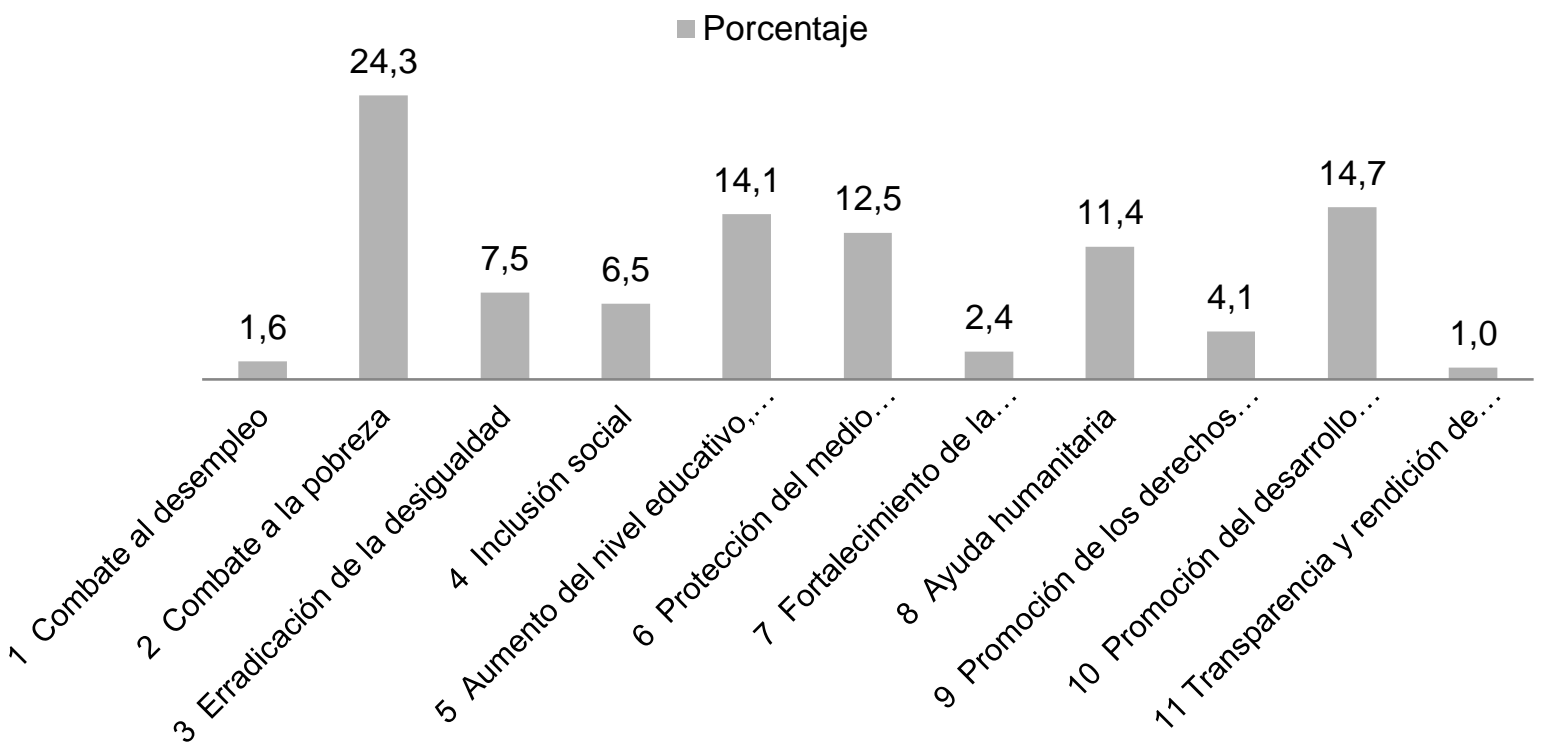

Fuente: elaboración propia

La segunda sección buscó información sobre la cooperación, pero en este caso centrada en México entorno a: características de la cooperación mexicana, relación con otros actores, temas relevantes de política pública, así como la percepción sobre el tipo de papel que debe jugar la cooperación del país en el exterior (donante, receptor o dual), y sobre sus fortalezas. Así, en términos generales, se percibe que nuestro país debe ser un actor dual en materia de cooperación internacional (48.8\% contestó que México debe contribuir con recursos financieros a la CID y $40.6 \%$ que debemos recibir) y que el 
Pérez, Jorge; Ayala, Citlali. Diagnóstico de cooperación internacional para el desarrollo mexicana y su andamiaje institucional actual.

gobierno debe tener un rol preponderante (55.9\%), pero se espera que comparar protagonismo con otros actores, como los organismos multilaterales de los que se espera más peso (66\%), la sociedad civil $(47.6 \%)$ o el sector privado $(40 \%)$.

En términos de prospectiva, partiendo de que la mayoría considera que México es un país dual en el presente (81\% así lo consideró), se espera que en los próximos diez años nuestro país tenga un mayor balance entre una posición dual (59\%) y una de socio donante (23\%), tal y como se refleja en las gráficas 3 y 4 . Finalmente, sobre las fortalezas de la cooperación mexicana, considerando las principales modalidades de la CID, se confirmaron las áreas de más tradición en nuestra cooperación como se observa en la gráfica 5, sobresaliendo: la cooperación sur-sur con $44.71 \%$, la cooperación triangular con $31.47 \%$ y la cooperación técnica con $24.7 \%{ }^{12}$.

\section{Gráfica 3}

En el ámbito de la Cooperación Internacional para el Desarrollo, considera que México es un país...

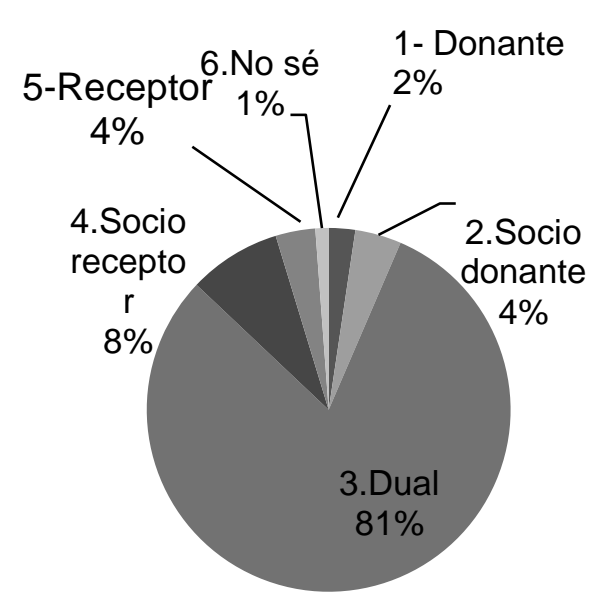

Fuente: elaboración propia
Gráfica 4

En los próximos 10 años, considera que México debería ser un país...

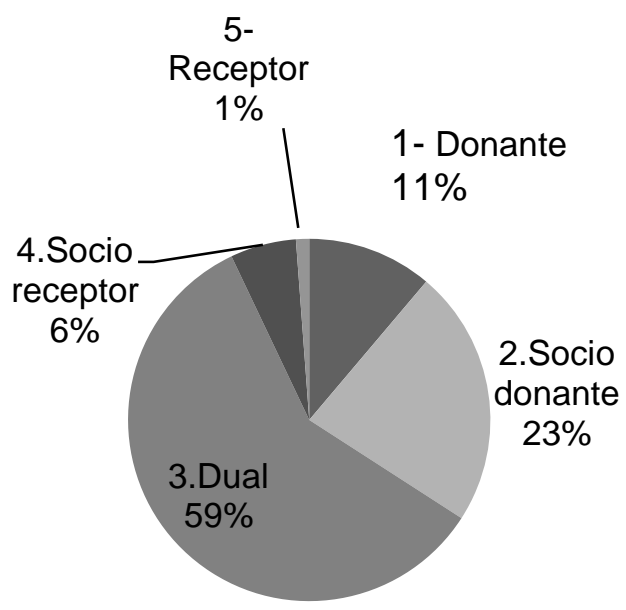

Fuente: elaboración propia

\footnotetext{
${ }^{12}$ Oficialmente, la cooperación sur-sur es la que otorgan los países en desarrollo a otros países en desarrollo y se basa en los principios de: horizontalidad (los países colaboran entre sí en términos de socios, de manera voluntaria y sin el establecimiento de condiciones), consenso (la ejecución de una acción de cooperación sur-sur debe haber sido sometida a consenso por los responsables de cada país en marcos de negociación común, como las comisiones mixtas), y equidad (por lo general, sus costos y beneficios se distribuyen equitativamente entre los participantes) (DOF, 2014).
} 
Pérez, Jorge; Ayala, Citlali. Diagnóstico de cooperación internacional para el desarrollo mexicana y su andamiaje institucional actual.

\section{Gráfica 5}

¿En cuáles de las modalidades de Cooperación Internacional para el desarrollo considera usted que México tiene actualmente una mayor fortaleza?

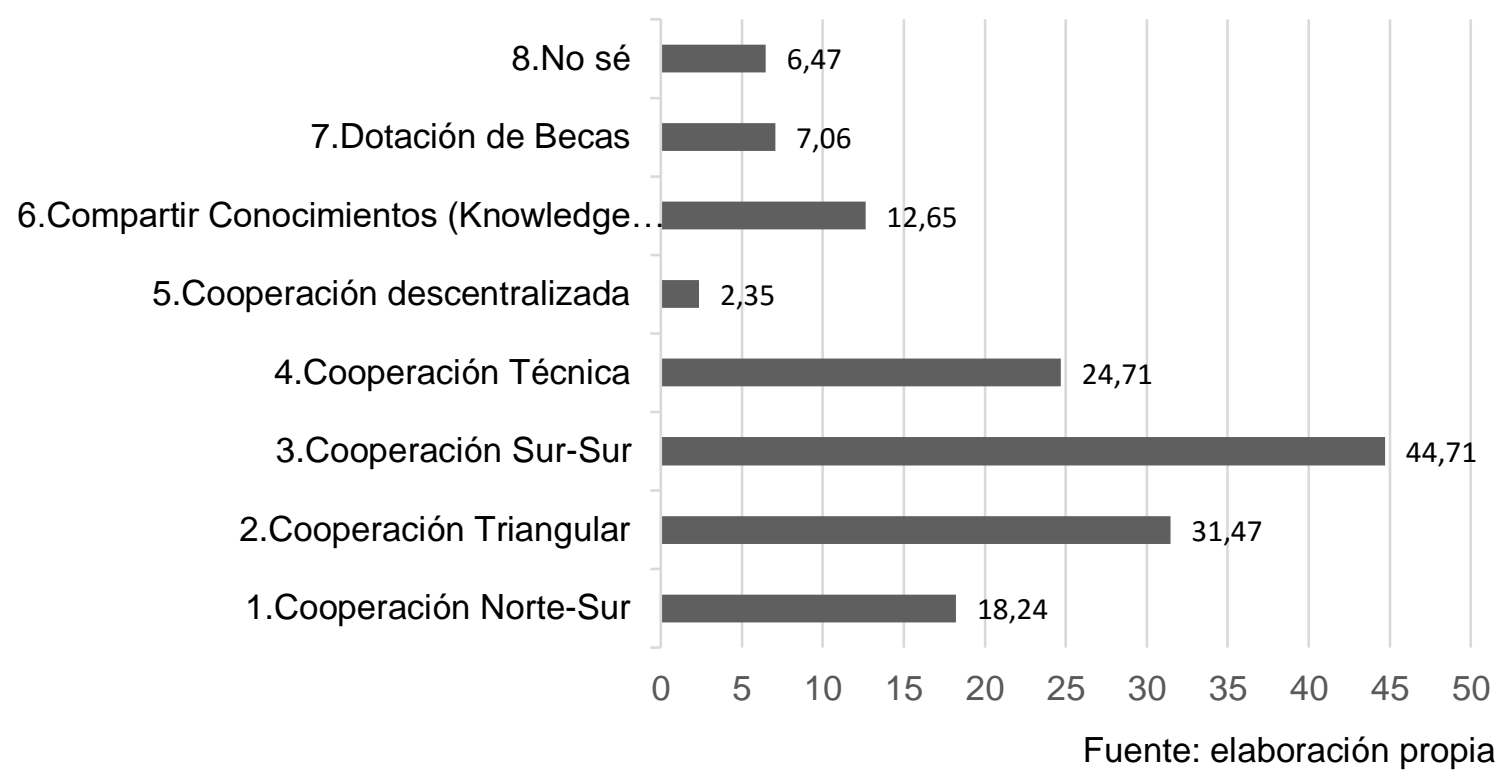

La última sección se centró en las opiniones y percepciones sobre el rol y funcionamiento de la AMEXCID. Al respecto, el $85 \%$ manifestó que si conoce o ha oído hablar de esta institución. Sobre las actividades de la agencia, la mayoría dio un mayor peso a que estas contribuyen y son relevantes para la sociedad, para el país y responden claramente a la política exterior, mostrando cierta indiferencia o neutralidad sobre aspectos como la transparencia, eficacia, eficiencia y visibilidad. Sobre los temas en los que debería orientar esfuerzos la agencia, se vuelve a coincidir en tres: combate a la pobreza como primera mención (26.5\%), aumento de la educación (18.8) como segunda mención (18.8\%) y promoción del desarrollo sustentable (11.8\%) (Ver gráfica 6). 
Pérez, Jorge; Ayala, Citlali. Diagnóstico de cooperación internacional para el desarrollo mexicana y su andamiaje institucional actual.

\section{Gráfica 6}

¿Cuáles deberian ser los temas más importantes para el pais desde la AMEXCID? (\%)

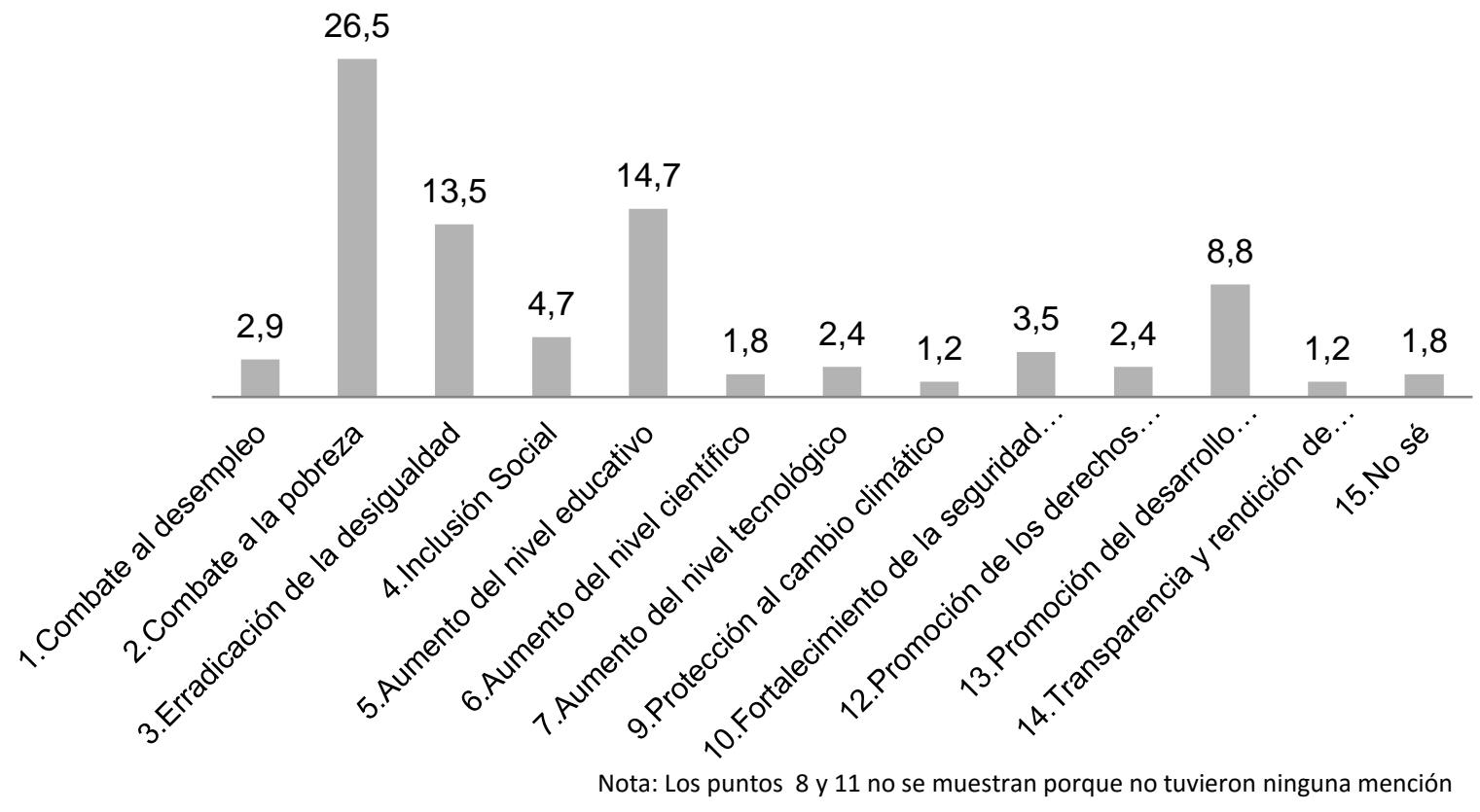

Fuente: elaboración propia

Por último, los encuestados consideran que la agencia debería recibir más fondos por parte del gobierno (71.2\%) (Gráfica 7), y orientar estos recursos adicionales, particularmente a la ejecución (50\%) y planeación de la CID (14\%) (Gráfica 8).

\section{Gráfica 7}

¿Considera que la AMEXCID debe recibir más fondos del gobierno?

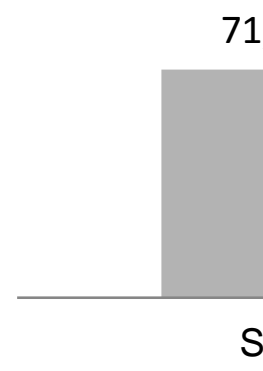

71,2

$$
\square \text { Porcentaje }
$$


Pérez, Jorge; Ayala, Citlali. Diagnóstico de cooperación internacional para el desarrollo mexicana y su andamiaje institucional actual.

\section{Gráfica 8}

¿Hacia dónde considera que deben canalizarse los fondos extra para lograr un desarrollo eficaz?

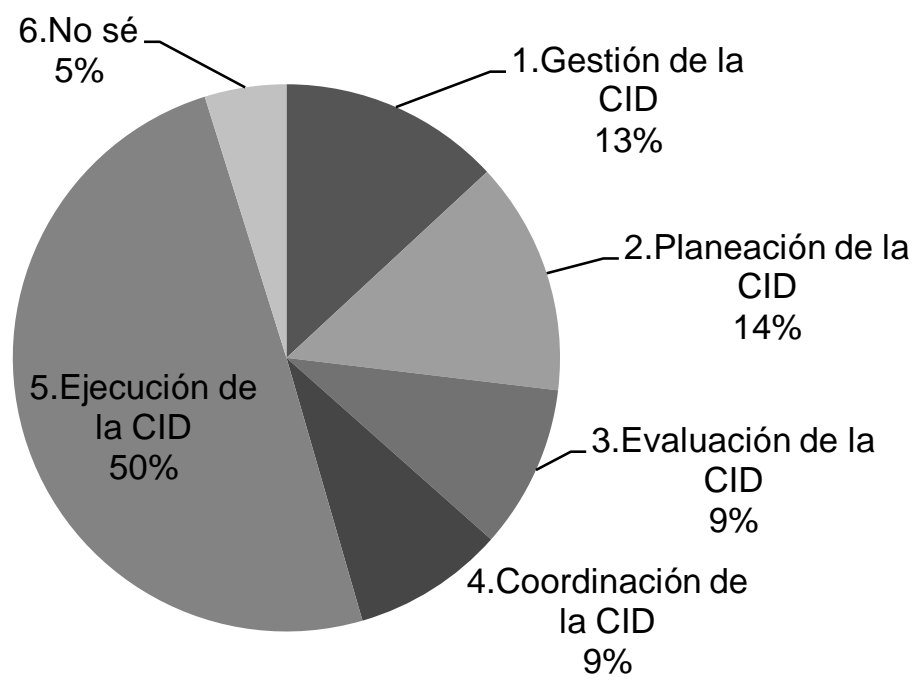

Fuente: elaboración propia

En particular, se puede confirmar que el trabajo de la cooperación internacional para el desarrollo en México debería estar dirigido prioritariamente al combate a la pobreza, la atención a la educación y la promoción del desarrollo sustentable. Considerando el papel de México como socio donante y/o como socio receptor, sobresale la importancia de las capacidades actuales en materia de cooperación técnica, y la necesidad de una mejor medición y rendición de cuentas, así como un mayor vínculo entre actores públicos, sociales y privados.

En ese sentido, se realizaron entrevistas a funcionarios y representantes de los ámbitos mencionados al principio de este artículo, mismas que se concentraron en tres preguntas concretas: (1) ¿Cómo considera que cambiará la Cooperación Internacional para el Desarrollo a partir de las negociaciones de la Agenda Post 2015 y el debate de la Alianza Global para la Cooperación eficaz al Desarrollo?; (2) ¿Cuáles considera que son los retos de la cooperación internacional mexicana desde su sector o campo de trabajo y, específicamente, desde la AMEXCID; y por último?, (3) ¿Cómo visualiza el papel de la Agencia Mexicana de Cooperación Internacional para el Desarrollo (AMEXCID) en los próximos 10 años? Las respuestas obtenidas permitieron identificar las prioridades y preocupaciones de cada sector.

Volviendo al análisis de los hallazgos específicos del estudio, lo que respecta a las entidades gubernamentales, a escala nacional se encontró interés en fortalecer el diálogo que derive en mayor trabajo con sociedad civil, sector privado y academia, a fin de implementar la nueva agenda de desarrollo los siguientes quince años, así como mantener coherencia en el marco delas agencias de Naciones Unidas. Asimismo, se mantiene la dualidad del país en la cooperación para el desarrollo. 
Pérez, Jorge; Ayala, Citlali. Diagnóstico de cooperación internacional para el desarrollo mexicana y su andamiaje institucional actual.

El gobierno del país señaló como los principales retos la apropiación del desarrollo, la transparencia, rendición de cuentas y coordinación de diversos actores; también la adecuada implementación del PROCID y la adhesión de más actores gubernamentales y no gubernamentales a la ejecución de la cooperación mexicana. Sería deseable en ese sentido que durante los siguientes diez años se reduzca el papel de receptor y se fortalezca el de donante emergente, así como la aportación presupuestal del gobierno en financiamiento de la cooperación internacional para el desarrollo. Ello implicaría un trabajo de lobby en el Congreso y con la Secretaría de Hacienda y Crédito Público, así como una sistematización de la demanda de cooperación al país por parte de los países socios estratégicos y los canales adecuados para su administración, idealmente a través del FONCID, todavía por salir a la luz. Finalmente, y no menos importante, generar un proceso de concientización de la sociedad mexicana sobre el tema de la cooperación internacional para el desarrollo.

A nivel sub-nacional, se halló que los gobiernos estatales y locales tienen interés en desarrollar acciones de cooperación internacional para el desarrollo, sin embargo, la ley actual no les dota de poderes ni facultades para ello. No obstante dicha situación, sí se están generando iniciativas para implementar la Agenda 2030 tal como se hizo con los ODM. Se espera, asimismo, la AMEXCID avance en un diseño institucional inclusivo, con un sistema de medición que considere el aspecto local e identificar avances, áreas de oportunidad y se desarrollen medidas de fortalecimiento de capacidades locales para la evaluación, el monitoreo y la rendición de cuentas. Esto derivaría en una coordinación entre los tres niveles de gobierno, frente a lo cual, además de mejorar la base jurídica, hace falta eliminar la corrupción para lograr la eficacia en el uso de los recursos.

Sobre la AMEXCID, los gobiernos locales desearían que en los próximos diez años se superara el reto de la continuidad transexenal y lograr una coordinación eficaz. Se aspiraría a que, casos como los hermanamientos, vayan acompañados de un programa de cooperación internacional para el desarrollo municipal, local, estatal, donde podría ayudar más la agencia que alguna otra institución o área de vinculación con gobiernos locales. Finalmente se considera que la CID debe ser una política pública en sí misma que derive en un programa coherente, alineado a la AGCED, que será un referente para los próximos años.

En el ámbito académico se encontró escasa vinculación con la Agenda de Desarrollo 2030 y sus antecedentes; prácticamente la cooperación educativa en el país lleva su propia agenda y la poca convergencia que se tiene es a través de la cooperación académica que gestiona la AMEXCID en sus programas bilaterales y regionales. Así, mientras las instituciones de educación superior realizan actividades de cooperación internacional, estas no necesariamente están vinculadas con el desarrollo y el combate a la pobreza, ni responden a la política exterior como sucede con la política de facto de cooperación internacional para el desarrollo. La comunicación con la SRE se distribuye en varias áreas de la estructura integral de la Cancillería, mas no hay exclusividad ni coherencia de políticas con AMEXCID. En ese sentido, se sugiere trabajar la visión y el fortalecimiento de la cooperación universitaria en la medida en que la AMEXCID se consolide. 
Pérez, Jorge; Ayala, Citlali. Diagnóstico de cooperación internacional para el desarrollo mexicana y su andamiaje institucional actual.

Lo que respecta a las organizaciones internacionales en México, la expectativa de entrar de lleno a la Agenda 2030 y fortalecer el papel de México en la cooperación sur-sur cobra mayor relevancia a la par de la necesidad de capacitar a las instituciones en medición, evaluación y seguimiento. Para tal efecto, se reconoce como necesario contar con una verdadera cultura de cooperación tanto a nivel institucional como social; también tener mayor certeza en lo que compone la política mexicana de cooperación para el desarrollo y su coordinación con la política exterior y con el desarrollo del país. Una vez que eso se encuentre mejor definido y divulgado, se esperaría que la agencia establezca una prioridad geográfica estratégica ya sea en Centroamérica o en otros países de América Latina, sin desdeño de regiones en pobreza extrema como algunos lugares de Asia y África. Un punto de especial interés para los próximos años será la administración de los recursos, una posible descentralización de los fondos, a fin de lograr una mayor cobertura nacional.

En el caso del sector privado, representado por una fundación, se hizo presente el problema de la constante reducción de recursos para el desarrollo, la falta de comunicación y coordinación con otros actores privados y el involucramiento en proyectos que combinen esquemas de negocios con donativos y prácticas no lucrativas. Además de la evidenciada necesidad de promover los esquemas de las alianzas público privadas, el sector de la filantropía tiene un papel importante en el desarrollo de la sociedad mexicana que no ha sido valorado. Esta reflexión podría dirigirse a la redistribución del poder, abrir canales de diálogo y empoderar a los más vulnerables, como es el caso de los indígenas. La política de cooperación que desarrolla la AMEXCID requiere estar mejor conectada con este sector, independientemente de si el país se fortalece como donante o continúa o no como receptor; se enfatizó la atención que requiere Centroamérica como espacio natural para los intereses y potencialidades de México.

Por último, en seguimiento a la configuración de la Agenda 2030, la sociedad civil organizada previó una mayor reducción o escasez de recursos públicos destinados a la cooperación al desarrollo, para lo cual se amerita claridad en la normatividad para el sector privado y su participación en la cooperación internacional. También se reconoció que no todas las organizaciones civiles mexicanas tienen idea de lo que es la CID y solo las que lo saben identifican que la AMEXCID es un interlocutor y uno puede ser un aliado con el cual trabajar o con el cual unirse en iniciativa de uno u otro; pero es una minoría. Un objetivo claro que persiga la AMEXCID dentro de su cartera de proyectos con donantes extranjeros sería incluir la creación de fondos para el fortalecimiento de la sociedad civil o la participación de esta. En perspectiva a diez años, las organizaciones de la sociedad civil tienen que buscar alternativas, pero se consolidarán como actores del desarrollo y eso solamente se logrará si se les reconoce y si la cooperación oficial incorpora la idea de que el desarrollo supone alianzas inclusivas. Sobre la relación con el área de la Secretaría de Relaciones Exteriores que atiende la vinculación con la sociedad civil organizada, se considera que mientras se mantenga esta diversidad de frentes cada uno con su lógica, no se avanzará mientras la AMEXCID mantenga la idea de que la cooperación es un elemento de relaciones internacionales y de política exterior. 
Pérez, Jorge; Ayala, Citlali. Diagnóstico de cooperación internacional para el desarrollo mexicana y su andamiaje institucional actual.

\section{CONCLUSIONES}

El estudio realizado provee información calve sobre tendencias de la cooperación mexicana, dando voz por primera vez, a las diferentes expresiones que participan en la cooperación, desde que se emitiera la Ley de cooperación internacional para el desarrollo en 2011. Además, el diagnostico provee datos que permitirán una mejor orientación en la toma de decisiones sobre, orientación y formulación de proyectos, programas y políticas.

Los resultados dan algunas pistas sobre los intereses, las necesidades y las potencialidades de la cooperación mexicana, aspectos que sin embargo, requerirán una profundización en un nuevo estudio que pueda identificar de forma sectorial los logros y avances de la institucionalidad de la cooperación mexicana, en un contexto que demanda evaluaciones, seguimiento y transparencia.

Entre los aspectos comunes a los actores entrevistados, y que se pueden plantear como retos y oportunidades para la cooperación mexicana, se podrían resaltar los siguientes: en cuanto a retos, no hay un consenso conceptual sobre lo que los distintos actores de la cooperación en México entienden por cooperación internacional para el desarrollo, por lo que será importante se genere un entendimiento común; no hay una cultura sobre lo que es la CID y los temas que abarca en nuestro país, razón que impide realizar este tipo de trabajo como un estudio de opinión a población abierta y más bien sólo con especialistas como sería el caso; no hay un mapeo o directorio sistematizado a nivel nacional que dé cuenta quién está realizando cooperación al desarrollo en México, además de las instituciones públicas o algunos otros actores identificados, de ahí la propuesta de ocho actores utilizada para fines de este estudio. Entre otros retos, los diferentes actores coinciden en el deseo de que la ley y la Agencia permitan la continuidad de la cooperación en el país, garantizar más fondos para estas actividades, lograr mayor coordinación entre actores y mayor rendición de cuentas.

Entre las oportunidades, se abre la posibilidad para que la Agencia asuma un mayor liderazgo al interior y al exterior del país, al tiempo de potenciar la oferta y demanda de cooperación que como país dual se espera que exista. La arquitectura actual y la implementación de la Agenda 2030 también permitirían una mayor planeación y alineación de la cooperación mexicana con la política exterior y a la política de desarrollo de forma más coherente. Asimismo, dicha agenda propiciaría focalizar mejor sus esfuerzos y la colaboración entre ellos a pesar de la diferencia en sus capacidades, acciones, facultades, recursos y conocimientos. Para ello, será de gran utilidad la consolidación de los consejos técnico y ad hoc de la AMEXCID, a fin de generar procesos más participativos. Por último, se espera que diagnósticos de esta naturaleza permitan promover más el tema de la CID en México y que eventualmente la opinión publica pueda participar de manera más informada, pues hasta ahora, parece ser que sólo públicos especializados conocen lo que acontece en nuestro país en materia de cooperación internacional. 
Pérez, Jorge; Ayala, Citlali. Diagnóstico de cooperación internacional para el desarrollo mexicana y su andamiaje institucional actual.

\section{BIBLIOGRAFÍA}

Alonso, J.A. (2012): "La evaluación en la cooperación internacional para el desarrollo", Revista Presupuesto y Gasto Publico 68/2012, 239-255. Instituto de Estudios Fiscales.

Alcázar, M.A. (2009): "Notas sobre la institucionalidad de la cooperación internacional en México", en Ayala, C. y Pérez, J. México y los países de renta media en la cooperación para el desarrollo: ¿hacia dónde vamos?, 115-135. Instituto Mora, FLACSO, CIDEAL, España.

Asociación Española de Pediatría: http://www.aeped.es/grupo-cooperacioninternacional/noticias/resultados-encuesta-sobre-cooperacion-internacional-2012

Ayala, C. y Pérez, J. (2009): "Balance de México en el proceso de institucionalización de la cooperación internacional para el desarrollo" en Ayala, C. y Pérez, J. México y los países de renta media en la cooperación para el desarrollo: ¿hacia dónde vamos?, 161-186. Instituto Mora, FLACSO, CIDEAL, España.

Carbonnier, G. y Sumner, A. (2012): "Reframing Aid in a world where the poor live in emerging economies", en Carbonnier, Gilles (Editor), International Development Policy: Aid, Emerging Economies and Global Policies, 3-18. Geneva, The graduate institute, Palgrave Macmillan.

Centro de Investigaciones Sociológicas de España:

http://www.cis.es/cis/opencms/ES/8_cis/boletines_PI/Boletin5/PDF/COOPERACI

ON.pdf

Cruz, N. (2008): "México en la cooperación internacional para el desarrollo del siglo XXI. Los nuevos retos" en Cuadernos de Trabajo de Posgrado. México. Instituto Mora 101-130.

DOF (2014): Diario Oficial de la Federación del 30 de abril de 2014, Estados Unidos Mexicanos, Programa de Cooperación Internacional para el Desarrollo 2014-2018. Recuperado de:

http://www.dof.gob.mx/nota_detalle.php?codigo=5342827\&fecha $=30 / 04 / 2014$

Duflo, E y Kremer, M. (2003): "Use of randomization in the evaluation of development effectiveness", escrito para World Bank Operations Evaluation Department (OED), Conference on Evaluation and Development Effectiveness. Washington. 1-37.

ECOSOC (2012): "Mutual accountability for development cooperation results: where next?", ECOSOC, DESA, draft study, New York, 1-32.

Fundación Carolina - Ce ALCI (2011): Barómetro 2010, América Latina y la cooperación al desarrollo en la opinión pública española. Recuperado de http://www.fundacioncarolina.es/wp-content/uploads/2014/08/DT49.pdf

González, L. (2005): La evaluación en la gestión de proyectos y programas de desarrollo, una propuesta integradora en agentes, modelos y herramientas. Cooperación Pública Vasca, Gobierno Vasco, Bilbao, España.

The Iris Association of Non-Governmental Development Organizations: http://www.dochas.ie/

Keohane, R. (1993): Instituciones internacionales y poder estatal. Ensayos sobre la teoría de las relaciones internacionales, Buenos Aires, Grupo Editor Latinoamericano, pp. 13-38. 
Pérez, Jorge; Ayala, Citlali. Diagnóstico de cooperación internacional para el desarrollo mexicana y su andamiaje institucional actual.

Klingebiel, S. (2014): Development cooperation: challenges of the new aid architecture. Palgrave Macmillan, UK. DOI: 10.1057/9781137397881.0001

Lozoya, J.A. (coord.), (1999): La nueva política mexicana de cooperación internacional. México, Instituto Mexicano de Cooperación Internacional para el Desarrollo.

Objetivos de Desarrollo del Milenio: http://www.un.org/es/millenniumgoals/bkgd.shtml

Ocampo, J.A. (2015): "A Post-2015 Monitoring and Accountability Framework", Department of Economic \& Social Affairs, CDP Background Paper No. 27, August, 1-17.

Ocampo, J.A. y Gómez, N. (2014): “Accountable and effective development cooperation in a post-2015 era”, ECOSOC, BMZ, DESA, Background Study 3.

Pauselli, G. (2013): "Teorías de relaciones internacionales y la explicación de la ayuda externa", Revista Iberoamericana de Estudios del Desarrollo, Volumen 2, número 1, (2013), pp. 72-92.

Prado, J.P. (2014): "La cooperación internacional para el desarrollo de México, un análisis de sus acciones, institucionalización y percepciones". Revista Mexicana de Ciencias Políticas y Sociales, Universidad Nacional Autónoma de México, nueva época, año LIX, num. 222, septiembre-diciembre, 51-86.

Red Iberoamericana de Protección Social:

http://redproteccionsocial.org/etiquetas/keywords/tercer-taller-sobre-politicasocial-y-cooperacion-internacional.

Salomón, M. (2001): "La teoría de las Relaciones Internacionales en los albores del siglo XXI: diálogo, disidencia, aproximaciones", Revista CIDOB D’Afers Internacionals 56, pp. 7-52, Barcelona.

Schiavon, J. (2014): Teorías de las Relaciones Internacionales en el siglo XX: Interpretaciones críticas desde México, Editores Jorge Alberto Schiavon Uriegas [et al.] Benemérita Universidad Autónoma de Puebla, El Colegio de San Luis, Universidad Autónoma de Baja California, Universidad Autónoma de Nuevo León, Universidad Popular Autónoma del Estado de Puebla. México.

Severino, J.M., Ray, Oliver, (2009): "The end of ODA: Death and rebirth of global public policy", Working Paper no. 167, Center for Global Development, March, Washington.

Soria, E. (2008): "La política mexicana de cooperación internacional para el desarrollo en el periodo 1988-2007: propuesta para la construcción de una política integral", en Schmukler, B., Ayala, C., y Sánchez, G. (coords.), Cooperación internacional para el desarrollo en México, hacia una agenda participativa. Instituto Mora, Miguel Ángel Porrúa, México, 23-104.

Sidiropoulos, E., Pérez-Pineda, J.A., Chaturvedi, S., Fues, T. (2015): Institutional Architecture \& Development: Responses from emerging powers. Jacana Media, South African Institute of International Affairs, South Africa.

UkAid (2010): Public Attitudes Towards Development. DFID, United Kingdom Recuperado:https://www.gov.uk/government/uploads/system/uploads/attachment _data/file/67684/public-attitudes-april10.pdf

Universidad de Cantabria (2010): Percepción de la comunidad universitaria de la UC sobre la cooperación internacional para el desarrollo y el comercio justo 2010 2011. Santander, España. 
Pérez, Jorge; Ayala, Citlali. Diagnóstico de cooperación internacional para el desarrollo mexicana y su andamiaje institucional actual.

Zarco, J., Castro, S.A., Martínez, X.A., (2015): "Panorama de los estudios de opinión sobre cooperación internacional", en Pérez-Pineda, J.A., Ayala, C, y De la O, F., Diagnostico sobre la cooperación internacional para el desarrollo en México 20142015. Instituto Mora, México D.F., 21-37. 